\title{
Academic optimism of teachers, school engagement and educational aspirations of students from private and government schools
}

\author{
Shariqua Ahmed ${ }^{\mathrm{a} *}$, Ritika Matta ${ }^{\mathrm{a}}$, Nandini Sanyal ${ }^{\mathrm{a}}$, Swati Agarwal $^{\mathrm{a}}$ \\ ${ }^{a}$ Department of Psychology, St. Francis College for Women, Hyderabad, Telangana, 500016, India
}

\begin{abstract}
This study aims to identify differences in private and government (public) schools concerning academic optimism of teachers and school engagement and aspirations among students. It aims to provide insight into the ability of teachers to influence engagement and aspirations among students by facilitating an environment conducive to academic engagement. Results indicate a difference between students of private and government schools in engagement and educational aspirations. Regression analysis explores the impact of academic optimism on certain aspects of school engagement while also highlighting a relationship between engagement and aspirations among students. Results indicate a need to look at teacher's academic optimism as a way of optimizing student ambition through active classroom instruction and various academic support networks.
\end{abstract}

Keywords: academic optimism; school engagement; educational aspirations; teachers; students

\section{Introduction}

Adolescence is a period of crucial development when children begin forming a sense of personal identity and agency about themselves. The often-confusing period of transition from a dependent child into an independently functioning adult encompasses a wide range of changes leading to the attainment of adult roles and responsibilities. Vygotsky (1978) considered this period as critical for the formation of one's reality of the world where an adolescent starts performing higher-level mental functions. This is made possible with guidance and approval from adults and peers acting as catalysts for better performance. As a child starts exploring the world outside and moves to middle or high school, they spend less time under their parent's supervision and are heavily influenced by their peers and teachers at school (Anderman, 2002). School becomes a prominent part of their life where they have a chance to develop close relationships with non-familial adults and enables them in assisting and sorting out independence and identity issues. Since teachers are most likely to be the primary non-familial adult in many adolescents' lives, the present study seeks to examine the impact that a teacher and their teaching beliefs have on a student's overall engagement that is comprised of his/her behavior, affect and cognition.

For a long time, schools have been in pursuit of methods to identify and overcome the obstacles that hinder student achievement (Hof, 2012). It is a well-accepted fact that while schools play a major role in student outcomes and achievement, a significantly large portion of this is attributable to the teachers who continue to

\footnotetext{
* Corresponding author.

E-mail address: shariqua.ahmed27@gmail.com
} 
provide a safe platform for the progressive development of abilities in a student. Teachers are thus crucial in the process of fostering independent thinking and problem-solving capacity in their students. There exists a strong relationship between what teachers believe about themselves, their students and how they impart education (Nietfeld \& Enders, 2003). Wu (2012) discusses the findings of several researchers who identified three school characteristics that were significantly related to student achievement: collective teacher efficacy, faculty trust in clients, and academic emphasis. These three attributes form the construct of academic optimism which is in turn, the outgrowth of several theoretical ideas one of which includes Martin Seligman's (1998) theory on learned optimism. Initially employed at the organizational level, academic optimism is now being considered at a more individual level. Hoy, Hoy, and Kurz (2008) conducted an exploratory study on how academic optimism could be a characteristic of teachers, rather than just organizations. Most research conducted in this area to date indicates that actions and styles of teachers are critical in creating caring communities in classrooms that are cohesive, supportive and involving. Noblit, Rogers and McCadden (1995) support this statement by explaining that "without a relationship with a teacher, a student has little reason to commit to instructional activities required by the curriculum".

One such student variable that is largely influenced by effective teaching and a facilitative school climate is school engagement. School engagement has also been defined as "participation in educationally effective practices, both inside and outside the classroom, which leads to a range of measurable outcomes.". Fredricks et al. (2003) identify three dimensions to student engagement- behavioral, emotional, and cognitive engagement. Students' perceptions of various aspects of the classroom social environment often include teacher academic and emotional support. A classroom's social environment is greatly influenced by a teacher and essential in cultivating optimal student engagement (Patrick, Ryan \& Kaplan, 2007). The growing interest in the construct of school has attracted a lot of research on how engagement is related to various outcomes such as higher academic achievement, higher levels of competence, lower depression, and better personal adjustment (Hedvat, 2008). Research conducted by Callaway (2016) demonstrated a positive relationship between not only student engagement and their future aspirations but also highlighted the importance of the teacher-student relationship and family support for learning and future aspirations. Bora (2016) explains how every student has their aspiration towards education and occupation and this is related to their school environment.

Apart from attempting to gain insight into the influence of academic optimism on engagement and future aspirations, the current study also focused on the impact of the type of board governing the school and its effect on the variables involved in the study. Based on the ownership of the educational institutions, the Indian education system is segmented into two major types: government (public) and private. Government schools are financed and managed by some level of government (either central or state). Private schools on the other hand are managed by an individual or a private organization and do not receive maintenance grants either from the government, a local body or any other public authority. Even though enrolment in government schools still dominates in the primary level, private schools have a greater share of student enrolment in the higher classes (The British Council, India, 2014). In recent years, India has seen a surge in the number of private schools also accompanied by growing gaps in the efficiency and effectiveness between private schools and government schools. Official figures obtained from the District Education Office of Hyderabad show that there are three times as many teachers in the private sector as in the government sector (Smith, Hardman \& Tooley, 2005). The present study aims to investigate these gaps concerning the academic optimism of teachers employed in government and private schools and simultaneously exploring the levels of school engagement and educational aspirations in students from government and private schools in the city of Hyderabad, India. 


\section{Methodology}

\subsection{Research Design}

A between-groups design was adapted to ascertain any differences between teachers from private and government schools with respect to teacher's academic optimism and its dimensions and differences between students from private and government schools with respect to school engagement and its dimensions and educational aspirations. Regression analysis was used to determine the predictors of school engagement and its dimensions and educational aspirations. Non-probability purposive sampling technique was used to select two samples for the study. The first sample consisted of 505 students from private (270) and government (235) Secondary School Certificate (S.S.C.) board schools. The second sample comprised 69 teachers who taught the selected student sample. Among them, 36 were from private schools and 33 were from government schools. The student sample consisted of 8th and 9th graders belonging to the age group of $11-17$ years $(M=13.67, S D=0.974)$.

\subsection{Instruments}

The Information Schedule: Participants were asked to fill in the information schedule which asked them about their age, gender, physical and psychological health, their parent's educational qualification, board of education, etc. Teachers were asked about their educational qualification, salary and number of teaching hours per week.

The Teacher Academic Optimism Scale-Secondary (TAOS-S): The Teacher Academic Optimism Scale-Secondary is a 9-item questionnaire which was devised by Fahy, Wu and Hoy (2010). The construct has three subscales: sense of teacher efficacy, teacher trust in parents and students and teacher sense of academic emphasis. The total teacher's academic optimism score is obtained by adding the scores of each dimension. According to Fahy, Wu and Hoy (2010) the alpha coefficients for efficacy, trust, and academic emphasis of teachers generated after conducting factor analysis were $0.85,0.87$ and 0.83 respectively.

School Engagement Scale: The 15-item School Engagement Scale was developed by Fredricks, Blumenfeld, Friedel and Paris (2003). It is a student self-report measure encompassing three areas: behavioral, emotional, and cognitive engagement. Participants were required to rate the responses on a 5-point Likert scale. According to Fredericks, Blumenfeld, Friedel and Paris (2003) the internal consistency values after conducting exploratory factor analysis for behavioral, emotional and cognitive engagement dimensions were found to be $0.72,0.83$ and 0.82 respectively.

Educational Aspiration Scale: The 8-item Educational Aspiration Scale was taken from the Career Aspiration Scale-Revised. The educational aspirations subscale refers to the degree to which people aspire to continue education or training within their career. The tool has a 5-point Likert scale and the total score for the scale was obtained by adding the scores of individual items. High scores reflect strong educational aspirations. The test-retest estimate for the educational aspiration subscale was 0.81 (Gregor \& O’Brien, 2016).

\subsection{Data Collection and Analysis}

Principals/coordinators of each school were approached in person to obtain permission for data collection in their schools. Students from grades eight and nine were made aware that their participation in the study was purely voluntary and were also assured that confidentiality would be maintained throughout the study. Those who agreed to participate in the study were requested to sign an informed consent form followed by the information schedule, school engagement scale and educational aspirations scale. The next step involved approaching the teachers who were either currently teaching the selected grades or had taught them in the previous academic year. The teachers were also briefed about the informed consent and confidentiality. 
Those who agreed to take part in the study were asked to fill out the informed consent form, the information schedule and the teacher academic optimism scale. After completion of data entry into the Statistical Package for Social Sciences (SPSS) version 20.0., scores were computed according to the scoring procedures of the tools. The teacher scores were segregated according to the class of students they taught. Means were then computed to get an overall academic optimism score and also dimension-wise scores. This process resulted in a final data sheet consisting of student scores mapped with the scores (overall academic optimism score and dimension-wise scores) of their teachers. The data was then analyzed using descriptive statistics, independent samples t-test, and regression analysis.

\section{Results}

Independent samples $t$-test was used to determine if there are any differences in private and government school teachers with respect to teacher's academic optimism and its dimensions. It was also used to determine whether there are any differences in private and government school students with respect to school engagement and its dimensions and educational aspirations. This was followed by simple linear regression analysis which was used to determine if teacher's academic optimism and its dimensions predict school engagement and its dimensions. Stepwise multiple regression was then used to ascertain the predictors of educational aspirations.

Table 1. Mean, Standard Deviation and the $t$-value for teacher's academic optimism and its dimensions in school teachers $(\mathrm{N}=69)$.

\begin{tabular}{|c|c|c|c|c|c|}
\hline \multirow[t]{2}{*}{ Variable Studied } & \multicolumn{2}{|c|}{$\begin{array}{l}\text { Private Schools } \\
\qquad(\mathrm{N}=36)\end{array}$} & \multicolumn{2}{|c|}{$\begin{array}{c}\text { Government } \\
\text { Schools } \\
(\mathrm{N}=33)\end{array}$} & \multirow[t]{2}{*}{$t$} \\
\hline & Mean & SD & Mean & $\mathrm{SD}$ & \\
\hline Teacher's Academic Optimism & 48.58 & 4.08 & 46.79 & 5.31 & 1.56 \\
\hline Sense of Teacher Efficacy & 24.06 & 2.39 & 23.67 & 2.79 & 0.62 \\
\hline Teacher Trust in Parents and Students & 11.94 & 2.06 & 11.67 & 1.69 & 0.62 \\
\hline Teacher Sense of Academic Emphasis & 12.58 & 1.52 & 11.45 & 2.69 & $2.12 *$ \\
\hline
\end{tabular}

Note: ${ }^{*} \mathrm{p} \leq 0.05$

The results in Table 1 indicate that there was a difference between teachers from

Table 2. Mean, Standard Deviation and the $t$-value for school engagement and its dimensions and educational aspirations in school students $(\mathrm{N}=505)$.

\begin{tabular}{llcccc}
\hline \multicolumn{1}{c}{ Variable Studied } & \multicolumn{2}{c}{$\begin{array}{c}\text { Private Schools } \\
(\mathrm{N}=270)\end{array}$} & \multicolumn{2}{c}{ Government Schools } \\
& \multicolumn{2}{c}{ Mean } & SD & Mean & SD \\
& 53.88 & 8.28 & 62.68 & 7.32 & $\mathbf{- 1 2 . 6 7 * *}$ \\
\hline School Engagement & 15.4 & 2.60 & 17.42 & 2.45 & $\mathbf{- 8 . 9 8 * *}$ \\
Behavioral Engagement & 22.74 & 4.03 & 26.41 & 3.07 & $\mathbf{- 1 1 . 5 9 * *}$ \\
Emotional Engagement & 15.74 & 4.27 & 18.85 & 4.11 & $\mathbf{- 8 . 3 4 * *}$ \\
Cognitive Engagement & 23.46 & 5.80 & 25.89 & 5.75 & $\mathbf{- 4 . 7 1 * *}$ \\
Educational Aspirations & & & & &
\end{tabular}

Note: $* * \mathrm{p} \leq 0.01$ 
private and government schools with respect to teacher sense of academic emphasis $(t=2.12)$ with teachers from private schools $(\mathrm{M}=12.58, \mathrm{SD}=1.52)$ scoring higher than teachers from government schools $(\mathrm{M}=11.45, \mathrm{SD}=2.69)$. The results in Table 2 depict that there was a difference between students from private schools and government schools with respect to school engagement $(t=-12.67)$, behavioral engagement $(t=-$ 8.98), emotional engagement $(t=-11.59)$, cognitive engagement $(t=-8.34)$ and educational aspirations $(t=-4.71)$. According to the mean scores in table 2, government school students scored higher than the private school students with respect to all variables considered for the present study.

The next section focuses on the simple regression analyses aimed at determining the predictors of school engagement and its dimensions (behavioral engagement, emotional engagement and cognitive engagement).

Table 3. Summary of Simple Regression Analyses for variables predicting school engagement and its variables in students from private schools $(\mathrm{N}=270)$

\begin{tabular}{|c|c|c|c|c|c|}
\hline & \multirow[b]{2}{*}{ Predictor Variables } & \multicolumn{4}{|c|}{ Criterion Variables } \\
\hline & & $\begin{array}{c}\text { School } \\
\text { Engagement }\end{array}$ & $\begin{array}{c}\text { Behavioral } \\
\text { Engagement }\end{array}$ & $\begin{array}{c}\text { Emotional } \\
\text { Engagement }\end{array}$ & $\begin{array}{c}\text { Cognitive } \\
\text { Engagement }\end{array}$ \\
\hline \multirow{4}{*}{$\beta$} & Teacher's Academic Optimism & $0.27 * *$ & 0.05 & $0.17 * *$ & $0.33 * *$ \\
\hline & Sense of Teacher Efficacy & $0.24 * *$ & -0.003 & $0.15 * *$ & $0.33 * *$ \\
\hline & Teacher Trust in Parents and Students & $0.22 * *$ & $0.16 * *$ & 0.07 & $0.26 * *$ \\
\hline & Teacher Sense of Academic Emphasis & $0.24 * *$ & 0.04 & $0.21 * *$ & $0.24 * *$ \\
\hline \multirow{4}{*}{$\mathrm{R}^{2}$} & Teacher's Academic Optimism & 0.07 & 0.002 & $\mathbf{0 . 0 3}$ & 0.11 \\
\hline & Sense of Teacher Efficacy & 0.06 & 0 & 0.02 & 0.11 \\
\hline & Teacher Trust in Parents and Students & 0.05 & $\mathbf{0 . 0 3}$ & 0.005 & 0.07 \\
\hline & Teacher Sense of Academic Emphasis & 0.06 & 0.002 & 0.04 & 0.06 \\
\hline
\end{tabular}

Note: $* * \mathrm{p} \leq 0.01, \beta-$ Standardized Coefficient Beta

Table 4. Summary of Simple Regression Analyses for variables predicting school engagement and its variables in students from government schools $(\mathrm{N}=235)$

\begin{tabular}{|c|c|c|c|c|c|}
\hline & \multirow[b]{2}{*}{ Predictor Variables } & \multicolumn{4}{|c|}{ Criterion Variables } \\
\hline & & $\begin{array}{l}\text { School } \\
\text { Engagement }\end{array}$ & $\begin{array}{l}\text { Behavioral } \\
\text { Engagement }\end{array}$ & $\begin{array}{l}\text { Emotional } \\
\text { Engagement }\end{array}$ & $\begin{array}{l}\text { Cognitive } \\
\text { Engagement }\end{array}$ \\
\hline \multirow{4}{*}{$\beta$} & Teacher's Academic Optimism & -0.04 & -0.09 & 0.03 & -0.03 \\
\hline & Sense of Teacher Efficacy & -0.02 & -0.1 & -0.02 & 0.04 \\
\hline & Teacher Trust in Parents and Students & 0.08 & 0.07 & $0.14 * *$ & -0.005 \\
\hline & Teacher Sense of Academic Emphasis & -0.07 & -0.07 & 0.03 & -0.1 \\
\hline \multirow{4}{*}{$\mathrm{R}^{2}$} & Teacher's Academic Optimism & 0.002 & 0.008 & 0.001 & 0.001 \\
\hline & Sense of Teacher Efficacy & 0 & 0.12 & 0 & 0.002 \\
\hline & Teacher Trust in Parents and Students & 0.006 & 0.005 & 0.02 & 0 \\
\hline & Teacher Sense of Academic Emphasis & 0.005 & 0.005 & 0.001 & 0.01 \\
\hline
\end{tabular}

Note: $* * \mathrm{p} \leq 0.01, \beta$-Standardized Coefficient Beta 
Table 5. Showing the summary of regression analyses for predictors of educational aspirations in students from private schools $(\mathrm{N}=270)$ government schools $(\mathrm{N}=235)$.

\begin{tabular}{|c|c|c|c|}
\hline & \multirow[b]{2}{*}{ Predictor Variables } & \multicolumn{2}{|c|}{ Criterion Variable (Educational Aspirations) } \\
\hline & & Private Schools & Government Schools \\
\hline \multirow{8}{*}{$\beta$} & Teacher's Academic Optimism & NS & $0.27 *$ \\
\hline & Sense of Teacher Efficacy & NS & NS \\
\hline & Teacher Trust in Parents and Students & NS & $0.18 * *$ \\
\hline & Teacher Sense of Academic Emphasis & NS & $-0.24 * *$ \\
\hline & School Engagement & $0.21 *$ & $0.47 * *$ \\
\hline & Behavioral Engagement & NS & NS \\
\hline & Emotional Engagement & NS & NS \\
\hline & Cognitive Engagement & $0.44 * *$ & NS \\
\hline \multirow{8}{*}{$\Delta \mathbf{R}^{2}$} & Teacher's Academic Optimism & NS & 0.01 \\
\hline & Sense of Teacher Efficacy & NS & NS \\
\hline & Teacher Trust in Parents and Students & NS & 0.03 \\
\hline & Teacher Sense of Academic Emphasis & NS & 0.05 \\
\hline & School Engagement & 0.02 & 0.22 \\
\hline & Behavioral Engagement & NS & NS \\
\hline & Emotional Engagement & NS & NS \\
\hline & Cognitive Engagement & 0.20 & NS \\
\hline \multicolumn{2}{|c|}{ Total Adjusted R² } & 0.21 & 0.30 \\
\hline
\end{tabular}

Note: ${ }^{*} \mathrm{p} \leq 0.05, * * \mathrm{p} \leq 0.01$, R-Coefficient of Correlation, $\Delta \mathrm{R}^{2}-\mathrm{R}$ Squared Change, $\beta$-Standardized Coefficient Beta

According to the results displayed in Table 3, teacher's academic optimism and all its dimensions emerged as predictors for school engagement as well as cognitive engagement among private school students. Behavioral engagement was predicted by teacher trust in parents and students. Emotional engagement was predicted by teacher's academic optimism, sense of teacher efficacy and teacher sense of academic emphasis. Results in Table 4 indicate that teacher trust in parents and students predicted emotional engagement among government school students.

Table 5 depicts the predictors of educational aspirations among private and government school students. With respect to the private school students, educational aspirations were predicted by cognitive engagement $(\beta=0.44, p \leq 0.01)$ and school engagement $(\beta=0.21, p \leq 0.05)$. Among both the predictors of educational aspirations, the contribution of cognitive engagement was $20 \%$ and the contribution of school engagement was found to be $2 \%$ and their contribution together was $21 \%$ of the overall variance of educational aspirations. In the case of government school students, school engagement $(\beta=0.47, p \leq 0.01)$, teacher trust in parents and students $(\beta=0.18$, $\mathrm{p} \leq 0.01)$, teacher sense of academic emphasis $(\beta=-0.24, \mathrm{p} \leq 0.01)$ and teacher's academic optimism $(\beta=0.27, \mathrm{p} \leq 0.01)$ were all found to be predictors of educational aspirations with contributions of $22 \%, 3 \%, 5 \%$ and $1 \%$ respectively and an overall contribution on $31 \%$. While school engagement, teacher trust in parents and students and teacher's academic optimism were positively correlated to educational aspirations, teacher sense of academic emphasis was negatively associated with it. 


\section{Discussion}

Results indicated a difference in the two groups of teachers with respect to teacher sense of academic emphasis; with teachers from private schools scoring higher on the dimension. This difference could be attributed to the teachers' perception of the outcomes that their efforts will yield. Since a significant number of students attending government schools belong to a lower socio-economic group, teachers may believe that their efforts have little or no influence on the performance of students and their academic aspirations. On the other hand, a plausible explanation for why teachers employed in private schools have a higher sense of academic emphasis could be due to the higher level of accountability in private schools. French and Kingdon (2010) studied how teacher quality may differ in government and private schools. According to their research, the heads of private schools in India have greater control over their staff and are thus able to exhibit tighter control over their activities in the school. The chain of accountability in a government school on the other hand is relatively much weaker, as the staff there has a permanent job with salaries and promotions independent of their performance levels (Goyal \& Pandey, 2009).

Levels of school engagement and educational aspirations differed between students belonging to private and government schools. Students from government schools scored higher on the aforementioned variables when compared to students attending private schools. Hardré, Sullivan, and Crowson (2009) explored the influence of selfperceptions and environmental perceptions of high school students in rural areas on their course-related interest, school engagement, and aspirations. Results showed that rural students saw the usefulness and value of what they were learning in school, and saw it as contributing toward achieving their goals. They were more likely to exhibit an interest in school and put forth effort into school-related activities probably because they perceived the content taught in school as instrumental to their futures. These findings could explain the higher levels of school engagement and its dimensions in students from government schools as noted in the present study.

Government school students seemed to have higher levels of educational aspirations as well. The work outlined by Moore (2014) could provide some insight into this outcome. Moore (2014) discussed the results of various studies suggesting that the purpose of education plays a very important role in determining the level of aspirations the student has. Sammons et al. (2016) explored the factors that influence students' aspirations and their beliefs about their academic capabilities. They also discuss how higher levels of unemployment in the students' neighborhood were associated with a higher probability of them considering higher education as a route to a stable future and a way of reducing the risk of unemployment. Students from government schools are mostly brought up in areas of high unemployment and taking into account the results suggested by the studies mentioned earlier, this could be one of the reasons for higher levels of educational aspirations of government school students in the present study.

Regression analysis was also used to ascertain the predictors of school engagement and its dimensions and also educational aspirations among students. Among government school students, emotional engagement was predicted by teacher's trust in parents and students. Trust, according to Rotter (1967), is crucial to all human learning. Students trust that teachers will help them learn. When students feel a sense of trust and optimism in their academic program, academic success is more easily achieved. Thus, trust is necessary for effective cooperation and communication and is essential to maximize the learning opportunities for a student.

From the multiple regression analysis done to determine the predictors of educational aspirations in students from private schools, both cognitive engagement and school engagement surfaced as predictors. In their study Veiga, Oliveira and Taveira (2014) suggested that students engaged in school present high academic aspirations and are motivated to explore career options. Such a suggestion is consistent with the finding of the present study that points to a positive relationship between engagement in school and students' academic aspirations and development. Litoiu (2015) discusses a similar notion emphasizing the direct impact of a teacher's 
involvement on their relationship with the students and their engagement in the classroom. Considering the results of the regression analyses mentioned above, it can be noted that while teacher's academic optimism predicts school and cognitive engagement, both these types of engagement further predict educational aspirations in students from private schools. This highlights a possible connection that suggests the role of academic optimism on the educational aspirations of students by facilitating their engagement in school.

For students belonging to government schools, it was seen that while teacher's academic optimism positively predicted educational aspirations, teacher's sense of academic emphasis negatively predicted educational aspirations. According to Callaway (2016), faculty members who share interests with students, tend to be more compassionate and exhibit concern, thus fostering student engagement and motivation which in turn helps students grow personally and professionally furthering their academic aspirations. While the findings of the aforementioned study indicate the importance of a positive teacher-student relationship and its impact on the aspirations of students, it fails to explain the reason why educational aspirations were negatively predicted by teacher's sense of academic emphasis in students from government schools. Since teachers from government schools scored lower on the dimension of teacher sense of academic emphasis while their students showed higher educational aspirations thus contributing to a negative relationship between the two variables. Another probable explanation for this finding can be explained by the ecological systems theory by Bronfenbrenner (1979). He explained how the psychological growth of a child is affected by multiple factors in his/her environment. Such a complex interaction of the adolescent and the school context could be one of the reasons for the aspirations of students from government schools to be influenced by factors other than the teacher-student relationship.

The present study highlights the importance of a healthy teacher-student relationship and how it facilitates behavioral, emotional and cognitive engagement and also fosters academic aspirations within students. The findings of the study show that the more the teacher makes an effort to make the learning process effective, more likely is the student to develop a positive approach towards his/her academic tasks which leads to greater school engagement and higher educational aspirations. It is recommended that school principals and teachers look at academic optimism as a way towards reaching the goal of academic success for students by facilitating active classroom instruction methods and various academic support networks. School administrators could provide common planning time for teachers and students to collaborate and share information about what would best meet their needs in the classroom. While all these are beneficial for the learning community in general, it is especially helpful to the disadvantaged students who need an optimistic learning environment to be successful.

Limitations and Scope: Student engagement in school and aspirations related to higher education are both developmental processes that are influenced by several contextual factors; one of them being the involvement of a teacher in facilitating student outcomes. While the data collected from the current sample of teachers used in this study provided insight into the teacher-student relationship, the sample only included teachers who were teaching the students in the present academic year and those who taught them in the previous academic year. Teachers who had taught the students during their primary and middle school years were not included in the study due to time constraints. These teachers would also have had an impact on the emotional and psychological development of the students contributing to their present levels of school engagement. Through the variable of educational aspirations, the present study evaluated the intentions of students from grades eight and nine to pursue higher education. Even though the students displayed high educational aspirations, it is difficult to know if they would stick with their current plans and actually attend college within the first two years after high school. This is especially relevant in the case of government school students who often drop out of school particularly after the tenth grade to supplement the family's income. Investigating the impact of academic optimism on school engagement and also confirming the patterns of predictions 
regarding the educational aspirations of students through a longitudinal study would help explore these variables over time.

\section{References}

1. Anderman, E. M. (2002). School effects on psychological outcomes during adolescence. Journal of educational psychology, 94(4), 795. http://dx.doi.org/10.1037/0022-0663.94.4.795

2. Bora, B. P. (2016). Educational and Occupational Aspiration In Relation To School Environment of the Secondary School Students of South Kamrup Area of Assam-A Study.

3. Bronfenbrenner, U. (1979). Contexts of child rearing: Problems and prospects. American psychologist, 34(10), 844. http://dx.doi.org/10.1037/0003-066X.34.10.844

4. Callaway, J. (2016). Student Engagement and College Students' Future Aspirations (Doctoral dissertation, Oklahoma State University). https://search.proquest.com/openview/fb8bfbb09f42fd57305aa93621634223/1?pqorigsite $=$ gscholar $\& \mathrm{cbl}=18750 \&$ diss $=\mathrm{y}$

5. Fahy, P. F., Wu, H. C., \& Hoy, W. K. (2010). Individual academic optimism of teachers: A new concept and its measure. Analyzing school contexts: Influences of principals and teachers in the service of students. Greenwich, CN: Information Age.

6. Fredricks, J. A., Blumenfeld, P., Friedel, J., Paris, A., (2003). School Engagement. Indicators of Positive Development Conference. Washington, DC: Child Trends. https://www.childtrends.org/wp-content/uploads/2013/05/Child_Trends2003_03_12_PD_PDConfFBFP.pdf

7. French, R., \& Kingdon, G. (2010). The relative effectiveness of private and government schools in Rural India: Evidence from ASER data.London: Institute of Education. https://econpapers.repec.org/scripts/redir.pf?u=https\%3A\%2F\%2Frepec.ucl.ac.uk\%2FREPEc\%2F pdf\%2Fqsswp1003.pdf; h=repec:qss:dqsswp:1003

8. Goyal, S., \& Pandey, P. (2009). How do government and private schools differ? Findings from two large Indian states. https://doi.org/10.11588/xarep.00003465

9. Gregor, M. A., \& O’Brien, K. M. (2016). Understanding career aspirations among young women: Improving instrumentation. The Journal of Career Assessment. 24(3), $559 \quad$ - 572. https://doi.org/10.1177\%2F1069072715599537

10. Hardré, P. L., Sullivan, D. W., \& Crowson, H. M. (2009). Student characteristics and motivation in rural high schools. Journal of Research in Rural Education (Online), 24(16), 1. https://jrre.psu.edu/sites/default/files/2019-08/24-16.pdf

11. Hedvat, A. T. (2008). Family and contextual variables as predictors of school engagement and developmental outcomes in adolescence. Boston College. http://hdl.handle.net/2345/615.

12. Hoy, A. W., Hoy, W. K., \& Kurz, N. M. (2008). Teacher's academic optimism: The development and test of a new construct. Teaching and teacher education, 24(4), 821-835. http://dx.doi.org/10.1016\%2Fj.tate.2007.08.004

13. Moore, K. S. (2014). The relationship between educational achievement and educational aspirations for Latino middle and high school students. California State University, Long Beach. https://search.proquest.com/openview/4dbc7c9486ecf72a17a232d08786c5b6/1?pqorigsite $=$ gscholar $\& \mathrm{cbl}=18750 \&$ diss $=\mathrm{y}$

14. Litoiu, N. (2015). The teachers and their representations about the students: what is beyond the labels?. Journal of Educational Sciences \& Psychology, 5(2).

15. Nietfeld, J. L., \& Enders, C. K. (2003). An examination of student teacher beliefs: Interrelationships between hope, self-efficacy, goal-orientations, and beliefs about learning. Current Issues in Education, 6, 1-36.

16. Noblit, G. W., Rogers, D. L., \& McCadden, B. M. (1995). In the meantime: The possibilities of caring. Phi Delta Kappan, 76(9), 680.

17. Patrick, H., Ryan, A. M., \& Kaplan, A. (2007). Early adolescents' perceptions of the classroom social environment, motivational beliefs, and engagement. Journal of educational psychology, 99(1), 83. https://psycnet.apa.org/doi/10.1037/0022-0663.99.1.83

18. Rotter, J. B. (1967). A new scale for the measurement of interpersonal trust. Journal of personality, 35(4), 651-665. https://psycnet.apa.org/doi/10.1111/j.1467-6494.1967.tb01454.x

19. Sammons, P. M., Toth, K., \& Sylva, K. (2016). Believing in better: How aspirations and academic self-concept shape young people's outcomes. http://hdl.voced.edu.au/10707/409150

20. Seligman, M. E. (1998). Building human strength: Psychology's forgotten mission. http://www.sagepub.com/sites/default/files/upm-binaries/11232_Chapter_1.pdf 
21. Smith, F., Hardman, F., \& Tooley, J. (2005). Classroom Interaction in Private Schools Serving Low-Income Families in Hyderabad, India. International Education Journal, 6(5), 607-618.

22. The British Council, India. (2014). Indian School Education System. An Overview. India. https://www.britishcouncil.in/programmes/schools/overview-school-education-system

23. Van Hof, J. (2012). Establishment and maintenance of academic optimism in Michigan elementary schools: Academic emphasis, faculty trust of students and parents, collective efficacy. Western Michigan University.

24. Veiga, F., Oliveira, Í. M., \& Taveira, M. D. C. (2014). Student's engagement in school, academic aspirations, and career exploration of Portuguese adolescents. In inted2014 conference (pp. 75457553). https://citeseerx.ist.psu.edu/viewdoc/download?doi=10.1.1.1031.818\&rep=rep1\&type=pdf

25. Vygotsky, L. S. (1978). Mind in society: The development of higher psychological processes. Cambridge, MA: Harvard University Press.

26. $\mathrm{Wu}, \mathrm{H}$. C. (2012). Collective responsibility, academic optimism, and student achievement in Taiwan elementary schools. The Ohio State University. http://rave.ohiolink.edu/etdc/view?acc_num=osu1332497667 